University of Nebraska - Lincoln

DigitalCommons@University of Nebraska - Lincoln

2001

\title{
Leader-Member Exchange and Its Dimensions: Effects of Self- Effort and Other's Effort on Relationship Quality
}

John Maslyn

Department of Leadership and Organizations, Vanderbilt University

Mary Uhl-Bien

University of Nebraska-Lincoln, mbien2@unl.edu

Follow this and additional works at: https://digitalcommons.unl.edu/managementfacpub

Part of the Management Sciences and Quantitative Methods Commons

Maslyn, John and Uhl-Bien, Mary, "Leader-Member Exchange and Its Dimensions: Effects of Self-Effort and Other's Effort on Relationship Quality" (2001). Management Department Faculty Publications. 17. https://digitalcommons.unl.edu/managementfacpub/17

This Article is brought to you for free and open access by the Management Department at DigitalCommons@University of Nebraska - Lincoln. It has been accepted for inclusion in Management Department Faculty Publications by an authorized administrator of DigitalCommons@University of Nebraska - Lincoln. 
Published in Journal of Applied Psychology 86:4 (2001), pp. 697-708; doi 10.1037/0021-9010.86.4.697 Copyright @ 2001 American Psychological Association. Used by permission. "This article may not exactly replicate the final version published in the APA journal. It is not the copy of record." http://www.apa.org/journals/apl/

An earlier version of this article was presented at the annual meeting of the Academy of Management, August 1999, Chicago, Illinois.

The authors gratefully acknowledge the helpful comments of Ronald Deluga while this research project was underway.

\title{
Leader-Member Exchange and Its Dimensions: Effects of Self-Effort and Other's Effort on Relationship Quality
}

\author{
John M. Maslyn \\ Department of Leadership and Organizations, Vanderbilt University \\ Mary Uhl-Bien \\ Department of Management, University of Central Florida
}

Correspondence - John M. Maslyn, Department of Leadership and Organizations, Box 514-GPC, Vanderbilt University, Nashville, Tennessee 37203; email maslynjm@ctrvax.vanderbilt.edu.

\begin{abstract}
Two hundred thirty-two manager-subordinate dyads provided data on the effort expended toward the development of leader-member exchange (LMX) relationships, how such effort related to expectations about relationship quality, and intentions to exert future effort toward relationship development. For both managers and subordinates, higher quality LMX relationships were reported and expectations were met when the other member of the dyad put forth effort into relationship development. One's own higher effort coupled with lower effort by the other was associated with a lower quality LMX relationship. Examination of the 4 dimensions of LMX (R. C. Liden \& J. M. Maslyn, 1998) revealed unique effects depending on the dimension considered. In addition, LMX and relationship tenure interacted, showing that future effort toward relationship development was greatest when individuals had been in higher quality relationships for longer periods of time.
\end{abstract}

Research on leader-member exchange (LMX) has shown the value of high-quality leader-member relationships in organizations (Graen \& Uhl-Bien, 1995; Liden, Sparrowe, \& Wayne, 1997). Leaders and followers in these high-LMX relationships often report enhanced levels of satisfaction and effectiveness, as well as mutual influence, more open and honest communication, greater access to resources, and more extra-role behaviors (Gerstner \& Day, 1997). Low-quality relationships, in contrast, appear to put subordinates at a relative disadvantage in terms of job benefits and career progress (Vecchio, 1997). In low-quality relationships, members receive less access to the supervisor, fewer resources, and more restricted information, potentially leading to dissatisfaction in the job, lower organizational commitment, and employee turnover (Gerstner \& Day, 1997).

Although LMX research has looked at differences in leadermember relationships and their effects on individuals and organizations, an area that has not received as much attention is dyad members' beliefs about how these relationships developed to the point they are currently (Graen \& Uhl-Bien, 1995). A growing body of research has examined antecedents and longitudinal development of LMX (e.g., Bauer \& Green, 1996; Deluga, 1998; Duchon, Green, \& Taber, 1986; Liden, Wayne, \& Stilwell, 1993), but an area absent in the literature has been investigation into the relative effort that individuals put into relationships to cause them to develop as they have, as well as individuals' beliefs about whether the relationship developed as they expected. These issues are important because they provide information about who is responsible for relationship development, whether the individuals feel they were able to develop the type of relationship they desired, and whether they intend to exert future effort into the relationship relative to current relationship quality.

The purpose of the present study was to investigate relative effort made toward relationship development in manager-subordinate relationships. Specifically, we examined managers' and subordinates' reports of their own and their dyad partner's effort toward relationship development and whether the relationship had developed as they expected. Subordinates also indicated how much future effort they intended to put into the relationship. Data were analyzed relative to LMX status (higher or lower LMX quality) and the dimensions of LMX identified by Liden and Maslyn (1998). The findings have significant theoretical and practical implications for how relationships develop.

\section{Effort in the Development of LMX Relationships}

Despite the volume of literature on the development of LMX relationships (for reviews, see Gerstner \& Day, 1997; Graen \& Uhl-Bien, 1995), most research on this topic continues to focus on the characteristics of leaders and followers, the interaction of these characteristics, and contextual variables (Liden et al., 1997). Examination of the social exchange processes that contribute to relationship development has been essentially left to theory (Rousseau, 1998). If research in this area is to advance, researchers must begin to empirically test issues related to social exchange in leader-member relationships (Liden et al., 1997; Uhl-Bien, Graen, \& Scandura, 2000). For example, researchers still do not know what the balance of effort is in LMXs. Do contributions to the relationship need to be seen as equal, or is LMX based on one party contributing 
more? Does the balance vary depending on whether we examine one's own effort versus effort by the other member of the dyad? Did dyad members make attempts to develop a quality relationship, and what are individuals' intentions in terms of exerting future effort into relationship development (e.g., in a low-quality relationship, do they keep trying, or do they quit?). Are these issues seen in the same way by both supervisors and subordinates?

Theoretical answers to these questions have been suggested in social exchange perspectives of LMX relationships (Dienesch \& Liden, 1986; Liden et al., 1997; Sparrowe \& Liden, 1997; UhlBien et al., 2000). In a direct application of social exchange theory (Blau, 1964; Homans, 1958; Mauss, 1950; Newcomb, 1961) to LMX, Liden and colleagues (Dienesch \& Liden, 1986; Liden et al., 1997) described leader-member relationship development as a series of steps that begins with the initial interaction between the members of the dyad. This initial interaction is followed by a sequence of exchanges in which individuals "test" one another to determine whether they can build the relational components of trust, respect, and obligation necessary for highquality exchanges to develop (Uhl-Bien et al., 2000). If reception of an exchange behavior (e.g., delegation) is positive and the party initiating the exchange is satisfied with the response (e.g., the subordinate made an appropriate decision), the individuals continue to exchange. If the response to an exchange is not positive (e.g., is not reciprocated or fails to show competence) or if exchanges never occur, opportunities to develop high-quality exchanges are limited, and relationships will likely remain at lower levels of LMX development (Dienesch \& Liden, 1986; Graen \& Scandura, 1987; Uhl-Bien et al., 2000).

Underlying all of these perspectives is the assumption that exchanges are based on effort exerted by the parties to the relationship (e.g., individuals exert effort to initiate exchanges, reciprocate exchanges, etc.). The relative effort that dyad members put forth and how this effort relates to LMX quality have not been examined, however. In one of the early experimental studies of LMX issues, leaders were trained to develop more effective exchanges with subordinates (Scandura \& Graen, 1984) by making an "offer" of a high-quality relationship, in other words, exerting effort into relationship development. When subordinates in low-quality LMX relationships saw this effort by managers, they responded positively, resulting in improvement in LMX quality. By design, the supervisors initiated the effort. However, we do not know how much effort supervisors put into the relationship, nor do we know the followers' roles in effort toward relationship building. This leaves unanswered the question of, in a naturally occurring manager-subordinate work relationship (i.e., one that does not follow a specific intervention designed to direct manager behavior), whose effort is more influential in the successful development of a high-quality LMX relationship - the supervisor, the subordinate, or both?

Besides the lack of empirical research, the issue of relative effort has not been clearly defined in the conceptual research on reciprocity and exchange in LMX. Consistent with social exchange theory (Blau, 1964), which states that when a person provides something of value to another person it obligates the recipient to reciprocate, LMX theory states that when a party makes an initial effort to develop the relationship (i.e., an "offer") this effort must be reciprocated through a series of exchanges. Blau noted, however, that such reciprocation is not always the case, such as when what is received is not valued or reciprocation is not possible. When no reciprocation happens repeatedly, the frequency of the valued offers diminishes. Because of this diminution, the key to effective relationship development according to social exchange and LMX perspectives is not necessarily who initiates the exchangesLMX theory is very clear that this process may start with either the manager or the subordinate (Uhl-Bien et al., 2000)but that there is initiation and reciprocation. From a dyad member's standpoint, he or she must see effort on the part of the partner, either in terms of initiation (i.e., a first step) or reciprocation (i.e., response to offers) for relationship development to proceed (Burgess \& Huston, 1979).

Although the present study is not an investigation of reciprocity, the preceding discussion has implications for LMX relative to effort. When one considers effort in LMX, a key variable is likely to be how much effort the dyad partner exerts. Regardless of how much effort individuals make toward relationship development, for their efforts to be successful there must be effort on the part of the partner (Burgess \& Huston, 1979). One can try and try, but if the partner does not put forth effort, the relationship will go nowhere (Blau, 1964). If this were not the case, that is, if own effort was the key variable in relationship development, then low-quality relationships would be a result of individuals consciously choosing to have a poor LMX - a situation that is unlikely given the negative consequences of these relationships (Gerstner \& Day, 1997).

On the basis of the preceding discussion, we suggest that a critical component of social exchange in LMX relationships is effort by the dyad partner (whether manager or subordinate), such that higher amounts of effort by the other will be positively associated with LMX:

Hypothesis 1a: For both managers and subordinates, a higher amount of effort by the dyad partner will be associated with higher LMX (after the effect of one's own effort is controlled for).

A related issue is the role of one's own effort in relationship development. As we mentioned earlier, social exchange perspectives indicate that relationships are more satisfying and stable when there is reciprocity and when rewards for each partner are more or less equal (Buunk, Jan Doosje, Jans, \& Hopstaken, 1993). Moreover, according to equity theorists, being either over- or underreciprocated in a relationship is accompanied by negative feelings (Walster, Walster, \& Berscheid, 1978). If the other person is not trying despite the fact that one is making an effort, one's own attempts are fruitless and may result in the individual developing a more negative view of the relationship (e.g., "I keep giving and giving but get nothing in return"). This latter situation may also be considered relative to "unbalanced overinvestment" relationships as described by Cogliser, Schriesheim, Scandura, and Neider (1999), in which individuals believe they exerted a great deal of extra-role activity in the relationship but the dyad partner does not perceive the same type of exchange. Such unbalanced exchanges were found to have less positive outcomes than balanced exchanges. Extending these concepts to relative effort, we can predict that the role of own effort will be particularly relevant in feelings about LMX relationships when effort by the other member is lower. In such cases, imbalances in exchange involving higher levels of own effort and lower other effort may represent to individuals their own futile attempts to develop relationships that are not reciprocated (Burgess \& Huston, 1979). 
Hypothesis 1b: For both managers and subordinates, there will be an interactive effect of own effort and other effort such that higher amounts of own effort and lower amounts of other effort will be associated with lower quality LMX.

\section{Effort and Dimensions of LMX}

With notable exceptions, LMX theory has considered the exchanges between members to be essentially work-related. That is, they consist of work-related behaviors such as effort toward the job or favorable task assignments. However, in a recent review of the LMX literature, Liden et al. (1997) noted that LMX is not based solely on the job-related elements emphasized in the LMX research of Graen and his colleagues (Graen \& Scandura, 1987; Graen \& Uhl-Bien, 1995) but may also include socially related "currencies." In this vein, Dienesch and Liden (1986) and Liden and Maslyn (1998) proposed four dimensions of LMX relationships labeled contribution (e.g., performing work beyond what is specified in the job description), affect (e.g., friendship and liking), loyalty (e.g., loyalty and mutual obligation), and professional respect (e.g., respect for professional capabilities). Other LMX research has produced measures of these constructs and demonstrated validity of these dimensions (Liden \& Maslyn, 1998; Schriesheim, Neider, Scandura, \& Tepper, 1992). Because LMX relationships may consist of one or more of these factors, examining the various dimensions of LMX might help us to further understand effort toward relationship development by managers and subordinates.

When the issue of effort is considered, exchange relationships based on various dimensions of LMX would likely show differences in terms of whose effort is most important. Consistent with the reasoning presented above, the amount of effort the dyad partner puts in will likely be important but perhaps differentially for each of the dimensions. According to Dockery and Steiner (1990) and Day and Crain (1992), supervisors and subordinates focus on different currencies of exchange from their partners: Supervisors seek more work-related currencies, and subordinates seek more socially related currencies. By using the dimensions, a more work-related currency is contribution, whereas the more social currencies would include affect, loyalty, and professional respect (Liden \& Maslyn, 1998). Extending this logic, then, we would expect that for subordinates, the amount of effort put forth by the manager (i.e., other's effort) would be positively related to the more "social" dimensions of affect, loyalty, and professional respect but not the more job-related dimension of contribution (Day \& Crain, 1992; Dockery \& Steiner, 1990). For managers, the amount of effort put forth by the subordinate (i.e., other's effort) would be positively related to contribution. Thus, for effort by the dyad partner, we predicted the following hypotheses:

Hypothesis 2a: Subordinates' reports of effort by the manager will be positively related to affect, loyalty, and respect (after we controlled for the effects of their own effort, and with contribution and the two dimensions not serving as dependent variables).

Hypothesis 2b: Managers' reports of effort by the subordinate will be positively related to contribution (after we controlled for the effects of their own effort and the affect, loyalty, and respect dimensions).

For one's own effort, we expected a slightly different picture. In terms of professional respect, and consistent with the rationale for Hypothesis $1 \mathrm{~b}$, we would expect both managers' and subordinates' own effort to be negatively related to respect, in that the more own effort they put in the lower the respect. In other words, having to put forth too much effort into the relationship would likely be associated with reduced respect for the other (e.g., "I had to put forth the effort myself, and it was the manager's/subordinate's role!"). For contribution, consistent with the aforementioned rationale for managers, we would expect subordinates' own effort to be more highly associated with a factor such as contribution ("I am putting effort into this relationship and so am willing to work harder beyond what is required by my job description"). One's own effort may not be as relevant for shared (or less objective) dimensions such as affect and loyalty. Therefore, we proposed the following hypotheses:

Hypothesis 2c: For both managers and subordinates, own effort will be negatively related to professional respect (after we controlled for effects of other's effort and the affect, loyalty, and contribution dimensions).

Hypothesis 2d: For subordinates, own effort will be positively related to contribution (after we controlled for the effects of own effort and the affect, loyalty, and respect dimensions).

\section{Effort and Met Expectations}

Although expectations have been explored in the LMX literature, it has been from the standpoint of expectations of competence and future achievement considered in the development of the relationship (Liden et al., 1993; Wayne, Shore, \& Liden, 1997; Whitener, Brodt, Korsgaard, \& Werner, 1998). If we look instead at whether expectations about the relationship were met, we do not know whether individuals report that the relationship developed as anticipated. We also do not know whether effort influences expectations or what happens to expectations when a poor relationship results. Therefore, an associated test of our prior hypotheses would be to examine whether expectations about the relationship were met relative to the effort put into the relationship.

Porter and Steers (1973) defined met expectations in terms of the discrepancy between what one encounters and what one expected to encounter. Consistent with earlier arguments and expanding the rationale behind Hypothesis 1, met expectations are more likely to be related to the effort of the other such that when the relationship did not develop as expected it was because of the other (or else expectations would have been met). In other words, reports of met expectations will be positively associated with other's effort, such that more effort by the dyad partner will be associated with higher met expectations (and vice versa). In addition, relative to own effort, met expectations will likely be negatively related to own effort such that when expectations are not met, individuals will report higher levels of own effort ("I tried and tried, but despite my efforts, expectations were not met").

Hypothesis 3a: For both managers and subordinates, effort toward LMX development by the other member of the dyad will be positively associated with met expectations.

Hypothesis 3b: For both managers and subordinates, the more effort one puts into relationship development (i.e., own effort), the lower the report of met expectations. 


\section{Future Effort Toward Relationship Development}

A final issue of interest is how one's current relationship affects intentions to exert future effort toward relationship development. If dyad members do not have a high-quality relationship, do they keep trying to achieve a high-quality relationship, or do they quit? Vecchio (1997) suggested that individuals in low-quality LMX relationships are virtually doomed to this status. Scandura and Graen (1984) found that lower quality LMX employees had the potential to perform better but did not make the effort - until the managers demonstrated effort toward the relationship and then LMX and performance improved. Although this research implies that those with lower quality exchanges may not try to improve their relationships (unless they see the dyad partner try), this has not been tested. In fact, the converse may be asked: If individuals already have a high-quality relationship, do they feel they no longer have to put effort into the relationship?

A factor that may be influential in answering this question is tenure in the relationship. ${ }^{1}$ Individuals who are in relationships longer (either higher or lower quality) are likely to be influenced differently than those who have been in relationships for shorter periods of time. Liden et al. (1997) proposed that the focus of members engaged in generalized reciprocity (high LMX) relationships is on further developing the relationship, even if they have been in the relationship for a longer time. In other words, as a positive relationship continues to develop, members would increasingly look to put in effort. Individuals whose relationships did not develop beyond lower levels and who have been in the relationship for a longer period of time are likely to exert little future effort, leaving them with a lower quality relationship.

Hypothesis 4: Intended future effort will be a function of subordinates' current LMX quality and tenure in the relationship, such that highest future effort will be reported by individuals who have had good relationships for longer periods of time.

\section{Method}

\section{Sample and Procedure}

Data were collected from employees operating in one division in the southeastern region of a large, international service organization. The sample consisted of front-line employees involved directly in service delivery to customers, managers up to four levels above these employees, and support staff. All respondents were asked to complete a questionnaire regarding their immediate managers (subordinate survey). Managers were then asked to complete a similar questionnaire about their subordinates (manager survey). Questionnaires were distributed over a 2-week period during meetings held by one of the researchers to describe the study and give participants time to complete the survey. In some cases, employees wanted to participate but were not able to attend meetings, so they were given the questionnaire with an envelope in which to return it to the researcher. Participation was voluntary, and confidentiality was assured.

The division of the organization from which we sampled had approximately 1,100 employees. After discussing with our research contact how to proceed with the study, we decided to randomly sample a subset of these employees by attending work unit meetings to distribute questionnaires. Employees were allowed to complete the survey on company time. As a result, 36 work groups with 25 different managers (these numbers are slightly different because 4

${ }^{1}$ We thank an anonymous reviewer for this suggestion. managers were responsible for more than 1 work group) comprising a range of job responsibilities were surveyed (approximately 25\% of the organization). Employees present at the meetings completed surveys, with a total of 280 subordinate surveys completed (survey completion was optional, and 18 of the 298 respondents in the meetings declined the opportunity to complete the survey). Some employees did not complete the subordinate survey in an appropriate manner, resulting in 6 unusable surveys. In addition, identification codes were missing on 16 subordinate surveys (6 were missing respondent identification codes and 10 were missing leader identification codes), so these surveys could not be used in the matched-sample analyses. A total of 276 manager surveys were returned. Of these surveys, 1 did not have a leader identification code, and 3 were unusable because the managers failed to complete the back side of the survey. This resulted in 232 matched manager-subordinate dyads, reflecting $78 \%$ of the total number of subordinates solicited. Because managers completed both manager and subordinate questionnaires, the subordinate analyses were run both with and without managers' responses (as subordinates) to determine whether participation as both supervisor and subordinate influenced the results. No differences were found; therefore, the overall sample included the managers' responses on the subordinate survey.

Respondents were primarily male (63\% were male, $26 \%$ were female, and $11 \%$ did not specify their sex) and between the ages of 20 and 35 years ( $22 \%$ were 25 or younger, $39 \%$ were between 26 and 35 , $21 \%$ were between 36 and $45,4 \%$ were between 46 and 55, and $2 \%$ were older than $55 ; 12 \%$ left this item blank). Ninety-two percent of respondents worked full-time, with $37 \%$ holding a bachelor's degree or higher $(16 \%$ had a high school degree or less, $10 \%$ had an associate's degree, $23 \%$ had some college, $29 \%$ had a bachelor's degree, $4 \%$ had some graduate work, $4 \%$ held a master's degree, and $14 \%$ did not respond to this question). Most of the sample was White (68\%), with 2\% Black, 7\% Hispanic, 3\% Asian, 2\% American Indian, and $6 \%$ "other" (12\% left this item blank). The average tenure with the company was 5.55 years $(S D=5.36$ years), and the average tenure with the supervisor was 10.0 months ( $S D=10.5$ months).

\section{Measures}

The subordinate measures included LMX quality (assessed with the LMX-7 [Graen \& Uhl-Bien, 1995] and the multidimensional leader-member exchange scale [LMX-MDM; Liden \& Maslyn, 1998]), own and other's effort put into relationship development, intentions to put forth future effort into relationship development, and met expectations about relationship quality. Because of space limitations and the number of surveys that managers needed to complete for multiple subordinates, managers were given a shortened version of the subordinate questionnaire. The manager measures included manager LMX, met expectations, and own and other's effort (but did not include LMX-MDM or future effort). The met expectations and effort measures were created specifically for this study because these issues had not been tested before in the LMX literature.

LMX. LMX was assessed by using two measures: the LMX-7 (Graen \& Uhl-Bien, 1995) and the LMX-MDM developed by Liden and Maslyn (1998). Because the LMX-MDM is a relatively new measure with limited published validation beyond the original work of Liden and Maslyn, reporting both measures allows us to examine the characteristics of the composite MDM relative to the LMX-7 to determine how each functions in the data analyses. Moreover, although the LMX-7 measure alone would provide a good basis for relationship quality, the LMX-MDM provides the opportunity to test the hypotheses relative to dimensions of LMX. Until we know more about the LMX-MDM composite measure, using both instruments allows us to examine overall LMX as well as its dimensions while strengthening the research findings and contributing to discussion of measurement issues in LMX.

The LMX-7 consists of 7 items that characterize various aspects of the working relationship between the supervisor and the subordinate, 
including effectiveness of the working relationship, understanding of job problems and needs, recognition of potential, and willingness to support the other $(\alpha=.90)$. The LMX-MDM is a 12-item measure $(\alpha=$ .92) containing four subscales ( 3 items per scale) of LMX dimensions. Affect evaluates the friendship and liking that the dyad member feels toward the other $(\alpha=.86)$, Loyalty evaluates the amount of loyalty the dyad member feels the other has toward him or her (e.g., "come to my defense"; $a=.80$ ), Contribution assesses the subordinate's willingness to put forth effort beyond what is required by the job description (e.g., "work my hardest" and "willing to apply extra efforts to meet my manager's work goals"; $\alpha=.66$ ), and Professional Respect assesses the amount of respect the individual has for the other regarding his or her job knowledge or competence $(\alpha=.84)$.

Finally, supervisors completed a mirror version of the LMX7 (manager LMX; $\alpha=.92$ ), worded to capture what the manager receives from the subordinate in the relationship (vs. past approaches that have primarily captured what the manager provides to the subordinate; e.g., Liden et al., 1993). We chose this approach to be consistent with the subordinate version, which captures what the subordinate receives from the manager. Sample items include "Do you know where you stand with this subordinate ... do you usually know how satisfied this subordinate is with what you do?" "How well does this subordinate understand your job problems and needs?" "Regardless of the amount of formal authority your employee has, what are the chances that he/she would "bail you out' at his/her expense?" and "What are the chances this subordinate would use his/her power to help you solve problems in your work?" Response categories were matched to the wording of each item. This measure showed both internal consistency (an exploratory factor analysis indicated one factor capturing $67 \%$ of the variance) and construct validity (a correlation of .46 with LMX, compared with the meta-analytic findings of a mean sample-weighted correlation of .29 between leader and member reports of LMX; Gerstner \& Day, 1997).

Effort into relationship development. Managers and subordinates were asked to think about their roles in LMX relationship development and then responded to two questions. The first question asked, "How much effort have you put into developing a good relationship with your manager [subordinate]?" This was labeled manager-reported effort or subordinate-reported effort. The second question asked, "How much effort has your manager [subordinate] put into developing a good relationship with you?" This was labeled manager reports of subordinate effort or subordinate reports of manager effort. Both items used a 5-point response format ranging from none at all to a great deal. Although the use of single-item measures can be problematic (see Schriesheim, Hinkin, \& Podsakoff, 1991), recent research on the equivalence of single-item measures with multiple-item measures of the same construct have shown that one can obtain equally valid ratings from either measure, depending on the issue being addressed (Gardner, Cummings, Dunham, \& Pierce, 1998; Wanous, Reichers, \& Hudy, 1997). Drawing from Sackett and Larson (1990), Wanous et al. (1997) noted, "If the construct being measured is sufficiently narrow or is unambiguous to the respondent, a single item may suffice" ( $p$. 247). Because what we were trying to assess was a relatively straightforward event (amount of effort exerted) rather than a less stable construct such as an attitude or a mood, our single-item measures should have sufficed in capturing the amount of effort exerted.

To provide further validation of our measures, however, we conducted a test-retest analysis to provide evidence of the stability of the measures. ${ }^{2}$ The effort items were administered twice to 68 fulltime working adults attending master's of business administration classes as part of a survey on relationships between subordinates and their managers. To test for a social desirability bias, the survey also contained a 10-item version of the Crowne-Marlowe (Crowne \& Marlowe, 1960) Social Desirability Scale (Strahan \& Gerbasi, 1972). The retest part of the survey was not given again until approximately 4 weeks later to reduce memory effects (Ghiselli,

\footnotetext{
${ }^{2}$ We thank an anonymous reviewer for this suggestion.
}

Campbell, \& Zedeck, 1981). The test-retest reliability, as indicated by the correlation between the same items at the two points in time, was .73 for reports of participants' own effort and .76 for reports of managers' effort. Correlations between the effort items and the social desirability measure were not significant (correlations at the two time periods ranged from -.07 to .13 ), suggesting that responses were not influenced by social desirability bias. These results support the reliability of the effort measures.

Future effort was measured for subordinates by using a four-item scale developed for this study. The questions asked how much effort the subordinate intended to put forth in the next month toward improving the relationship with the manager (5-point response format ranging from none at all to a great deal), the extent to which the respondent agreed that establishing an effective relationship was a top priority in the future, whether the subordinate was too busy to invest time in the relationship (reverse-scored), and whether the subordinate agreed with the statement "I do not have the energy to invest in this relationship" (the latter three items were rated on a 5-point agree-disagree scale). The 1-month time frame is consistent with other LMX research to capture potential relationship quality changes (e.g., 2 months by Bauer \& Green, 1996; 2 weeks, 6 weeks, and 6 months by Liden et al., 1993). Cronbach's alpha for the measure was 79 .

Met expectations. Met expectations of relationship quality were assessed by both managers and subordinates using similarly worded three-item measures asking whether the relationship had developed as expected, whether the relationship had disappointed the respondent (reverse-scored), and whether the relationship had surpassed his or her expectations (5-point agree-disagree response format). Cronbach's alpha for the subordinate version was .72, whereas for the manager version, it was .82 .

Dyadic tenure. Dyadic tenure was based on subordinates' reports of how long they had been working with their present manager (measured in months).

\section{Results}

The hypotheses were tested using multiple regression analysis, including hierarchical regression used to test the interaction hypotheses (Hypotheses $1 \mathrm{~b}$ and 4 ). Due to potential effects of various demographic variables on relationship quality (Bauer \& Green, 1996; Liden et al., 1993; Wayne, Liden, \& Sparrowe, 1994), subordinates' gender, age, level of education, and dyadic tenure were used as controls in the regression analyses. As we noted earlier, dyadic tenure was also examined more closely in the test of Hypothesis 4 because of its expected relationship with future effort.

Variable means, standard deviations, and intercorrelations are reported in Table 1, which shows that the mean levels of effort reported by managers and subordinates regarding their own effort and the effort of the dyad partner were above the scale midpoint with good variation. $T$ tests showed that subordinates' reports of their own and their dyad partner's effort did not differ, $t(259)=0.84, n s$, whereas managers' reports of their own effort were significantly higher than their reports of subordinates' effort toward relationship development, $t(271)$ $=5.84, p<.001$. The zero-order correlations indicate that both subordinates' and managers' reports of their own and their dyad partner's effort were positively associated with all measures of LMX.

Hypothesis 1a predicted that effort toward LMX development by the other member of the dyad would be positively associated with LMX when effort on the part of the respondent was being taken into account. This hypothesis was tested two ways. First, manager and subordinate evaluations of LMX 
Table 1. Means, Standard Deviations, and Correlations of Variables

\begin{tabular}{|c|c|c|c|c|c|c|c|c|c|c|c|c|c|c|c|c|c|c|c|c|}
\hline Variable & $M$ & $S D$ & 1 & 2 & 3 & 4 & 5 & 6 & 7 & 8 & 9 & 10 & 11 & 12 & 13 & 14 & 15 & 16 & 17 & 18 \\
\hline 1. LMX-7 & 3.77 & 0.78 & - & & & & & & & & & & & & & & & & & \\
\hline 2. Manager LMX & 3.72 & 0.74 & .46 & - & & & & & & & & & & & & & & & & \\
\hline 3. LMX-MDM (composite) & 4.02 & 0.60 & .80 & .42 & - & & & & & & & & & & & & & & & \\
\hline 5. LMX-MDM Affect & 4.13 & 0.67 & .69 & .42 & .86 & .55 & - & & & & & & & & & & & & & \\
\hline 6. LMX-MDM Loyalty & 3.81 & 0.76 & .79 & .39 & .89 & .62 & .70 & - & & & & & & & & & & & & \\
\hline 7. LMX-MDM Professional Respect & 4.02 & 0.76 & .69 & .33 & .88 & .58 & .70 & .68 & - & & & & & & & & & & & \\
\hline 10. Manager-reported effort & 3.84 & 0.88 & .36 & .48 & .28 & .21 & .27 & .27 & .21 & .20 & .29 & - & & & & & & & & \\
\hline 11. Manager reports of subordinate effort & 3.63 & 0.95 & .46 & .68 & .45 & .39 & .37 & .41 & .39 & .20 & .34 & .84 & - & & & & & & & \\
\hline 12. Met expectations (by subordinate) & 3.79 & 0.85 & .61 & .39 & .67 & .43 & .61 & .61 & .62 & .16 & .52 & .26 & .39 & - & & & & & & \\
\hline 13. Met expectations (by manager) & 3.88 & 0.91 & .35 & .60 & .30 & .27 & .22 & .31 & .22 & .16 & .28 & .29 & .50 & .26 & - & & & & & \\
\hline 14. Future effort & 3.69 & 0.71 & .42 & .25 & .50 & .52 & .35 & .42 & .45 & .41 & .31 & .07 & .25 & .21 & .14 & - & & & & \\
\hline 15. Dyadic tenure (months) & 10.04 & 9.19 & .15 & .31 & .19 & .15 & .20 & .19 & .11 & .03 & .06 & .12 & .15 & .11 & .16 & .21 & - & & & \\
\hline
\end{tabular}

Means and standard deviations of scaled variables were based on a 5-point scale, unless otherwise noted. Gender was coded $1=$ male and $2=$ female . Education was based on a 7-point scale ranging from 1 (high school or less) to 7 (master's degree or greater). The sample size based on listwise deletion was 182 (excluding correlations with demographics, for which $N=153$ ). All correlations $\geq .16$ are significant at $p<.05$. All correlations $\geq .20$ are significant at $p<.01$. LMX = leader-member exchange; MDM = multidimensional scale.

quality were regressed on judgments of effort as reported by the same source (e.g., subordinate-reported LMX regressed on subordinate-reported effort), and second, LMX quality as reported by each member of the dyad was regressed on the reports of effort from the other member. This second (crossdyad) method provides a test that removes the possibility of same-source bias between independent and dependent variables. Table 2 shows the results of these four analyses.

In the within-source analysis of manager and subordinate reports, effort by the other member was positively associated with LMX after we controlled for the effects of own effort, supporting Hypothesis 1a. In the cross-dyad analysis, both manager and subordinate reports of effort by the other member of the dyad were positively associated with relationship quality as reported by the separate source, also supporting Hypothesis 1a. Therefore, for both members of the dyad, LMX quality was related to effort by the other member of the dyad. This was a robust finding in that it was supported in both the within- and cross-dyad evaluations of the dependent variable.

Hypothesis $1 \mathrm{~b}$ addressed the effects of one's own effort and proposed that LMX would be lower when individuals reported higher amounts of own effort and lower amounts of effort by the other. The entry of the interaction term of one's own and the dyad partner's effort resulted in a significant increase in accounted variance in LMX for both subordinate and manager reports (within-source). Figure 1 shows regression lines of manager and subordinate effort toward LMX development at higher and lower levels of effort by the other member of the dyad (levels were based on $\pm 1 S D$ from the mean for each variable; Cohen \& Cohen, 1983). For subordinates, one's own higher effort coupled with lower effort by the manager was associated with a lower quality relationship. The effect was more dramatically shown in the manager data. When managers reported effort toward a subordinate who exerted lower levels of effort, this was associated with lower LMX quality. These findings were not replicated when the dependent variable was assessed by the dyad partner. Therefore, Hypothesis $1 b$ was supported by the within-source data but not the cross-dyad analyses. ${ }^{3}$

The second set of hypotheses addressed the relationship between effort and the LMX-MDM dimensions. Because the LMX-MDM data were available only from subordinates, two sets of analyses were run: one with subordinate reports of effort and subordinate-reported LMX-MDM (within-source), and the other with manager reports of effort and subordinatereported LMX-MDM (cross-dyad). As we expected, the findings revealed unique effects for some of the dimensions (see Table 3).

Hypotheses $2 \mathrm{a}$ and $2 \mathrm{~b}$ addressed effort by the dyad partner in predicting LMX dimensions. We expected that subordinates' reports of manager effort would be positively related to affect, respect, and loyalty (Hypothesis 2a) and that managers' reports of subordinate effort would be positively related to contribution (Hypothesis 2b). We tested these hypotheses by using the most stringent analyses, removing the effects of the other dimensions and controlling for the respondents' own

\footnotetext{
${ }^{3}$ We tested the effect of number of subordinates each manager evaluated on the findings for dyad member effort and LMX (Hypotheses $1 \mathrm{a}$ and $1 \mathrm{~b}$ ). This test divided managers into two groups: those with fewer than 11 subordinates and those with 11 or more subordinates. In the resulting eight analyses (two within-dyad and two acrossdyad for both the larger and smaller groups), we replicated our initial findings and supported our hypothesis regarding the importance of other's effort as a predictor of relationship quality in all but one case: The subordinate reports of effort in predicting LMX quality reported by the manager showed significance for other's effort at $p<.11$. This result occurred in the small group sample, which had a low sample size (54 dyads). In all analyses, the interaction hypothesis was not supported, possibly due to the loss of power from splitting the sample. On the basis of this cross-validation across the samples, we are confident that there was no systematic effect associated with the number of subordinates each manager evaluated.
} 
Table 2. Hierarchical Regression Analysis of Subordinate and Manager Reports of Leader-Member Exchange (LMX) on Subordinate and Manager Reports of Effort.

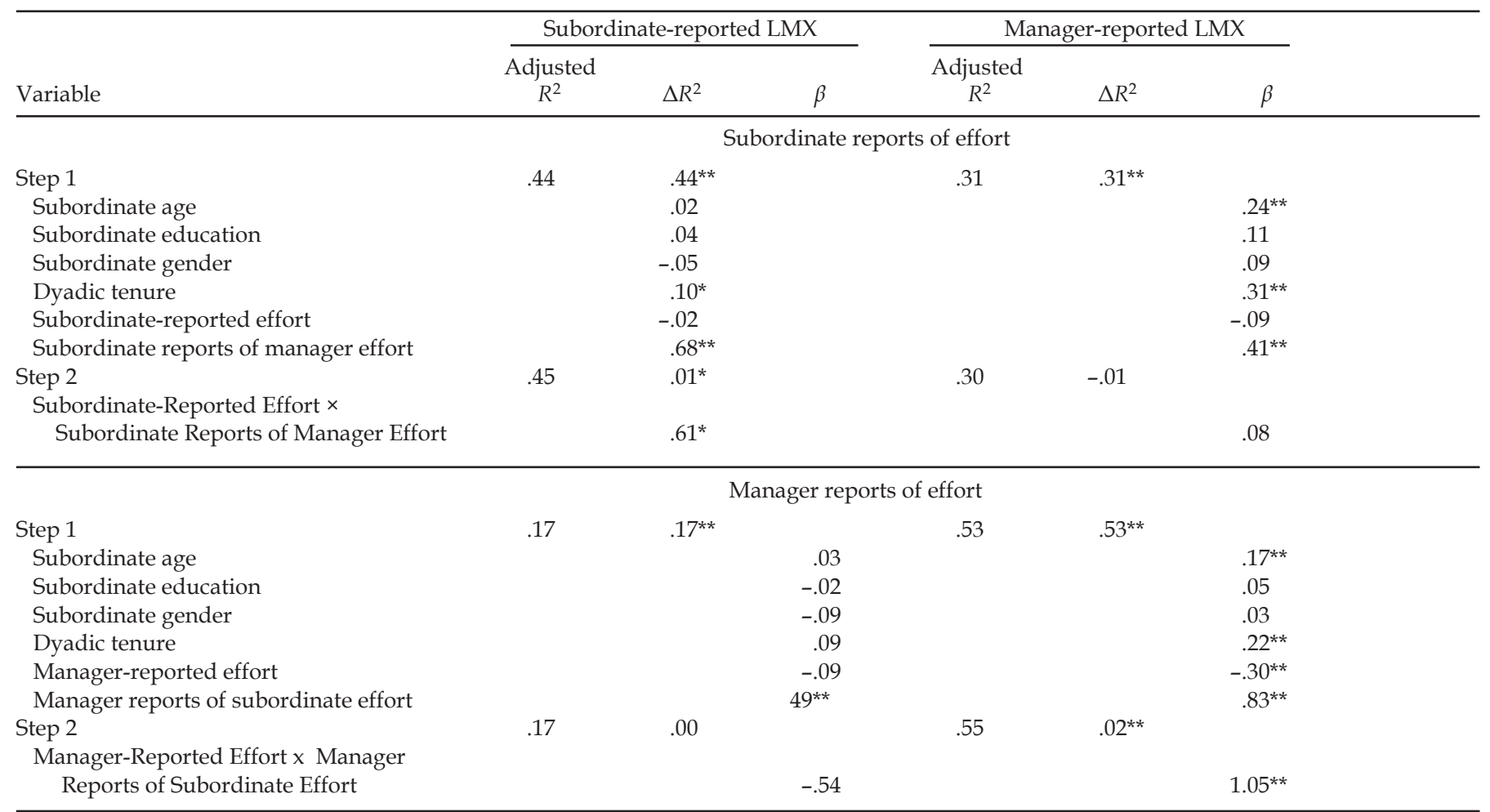

Degrees of freedom at Step 1 were 6, 203 and 6, 175 for the subordinate reports of effort with LMX and manager LMX, respectively, and 6, 178 and 6, 184 for the manager reports of effort with LMX and manager

LMX, respectively. Gender was coded $1=$ male and $2=$ female .

${ }^{*} p<.05 .{ }^{* *} p<.01$.

effort. Findings indicate partial support. For subordinates, reports of effort on the part of the manager were positively related to professional respect and loyalty but not affect (supporting Hypothesis 2a for respect and loyalty but not affect). Manager-reported effort by subordinates was not significantly related to contribution, failing to support Hypothesis $2 \mathrm{~b}$. In addition, though not predicted, managers' reports of subordinate effort were also positively related to respect, mirroring the findings using subordinates' reports of effort.

Hypotheses $2 \mathrm{c}$ and $2 \mathrm{~d}$ addressed predictions related to levels of one's own effort in relationship development. In support of both of these hypotheses, results showed that after we controlled for the effects of other dimensions and effort by the dyad partner, for both managers and subordinates one's own effort was negatively related to professional respect (Hypothesis 2c), and for subordinates one's own effort was positively related to contribution (Hypothesis $2 \mathrm{~d}$ ).

Because the results for professional respect might suggest a curvilinear relationship or suppressor effect caused by reports of the dyad partner's effort, we tested for both of these. The results of these analyses (Pedhazur, 1982) were not significant. Overall, in examining dimensions of LMX, the findings varied slightly from those for LMX (using LMX-7), suggesting the value of examining dimensions to gain a more specific understanding of differential effects of components of LMX that would not be demonstrated by the overall LMX alone.

Hypothesis 3a predicted that, for both managers and subordinates, effort by the dyad partner toward relationship de- velopment would be positively related to met expectations (controlling for one's own effort). Again, this hypothesis was tested using both same-source and cross-dyad analyses. Generally consistent with the findings for effort and LMX, Hypothesis 3 a was supported for both managers and subordinates in the same source analysis. The cross-dyad analysis indicated support for the regression of subordinate-reported met expectations on the managers' reports of effort but not in the prediction of the managers' met expectations using subordinate reports of effort (see Table 4). Therefore, Hypothesis 3a received support in three of four analyses in which effort by the dyad partner was positively associated with met expectations of subordinates and managers.

For reports of one's own effort and met expectations, we predicted that reports of one's own effort would be negatively associated with met expectations (Hypothesis $3 b$ ). The regression results (controlling for effort by the other) indicate that one's own effort in relationship development was negatively related to met expectations for subordinates and managers, showing that the more effort they put in themselves, the less their expectations were met. The same-source and cross-dyad analyses showed the same pattern as with reports of effort by the dyad partner: Each analysis supported Hypothesis $3 \mathrm{~b}$ with the exception of the regression of managers' met expectations on subordinate reports of effort.

Finally, Hypothesis 4 predicted that subordinate future effort toward relationship development would be associated with an interaction between the subordinates' current LMX 

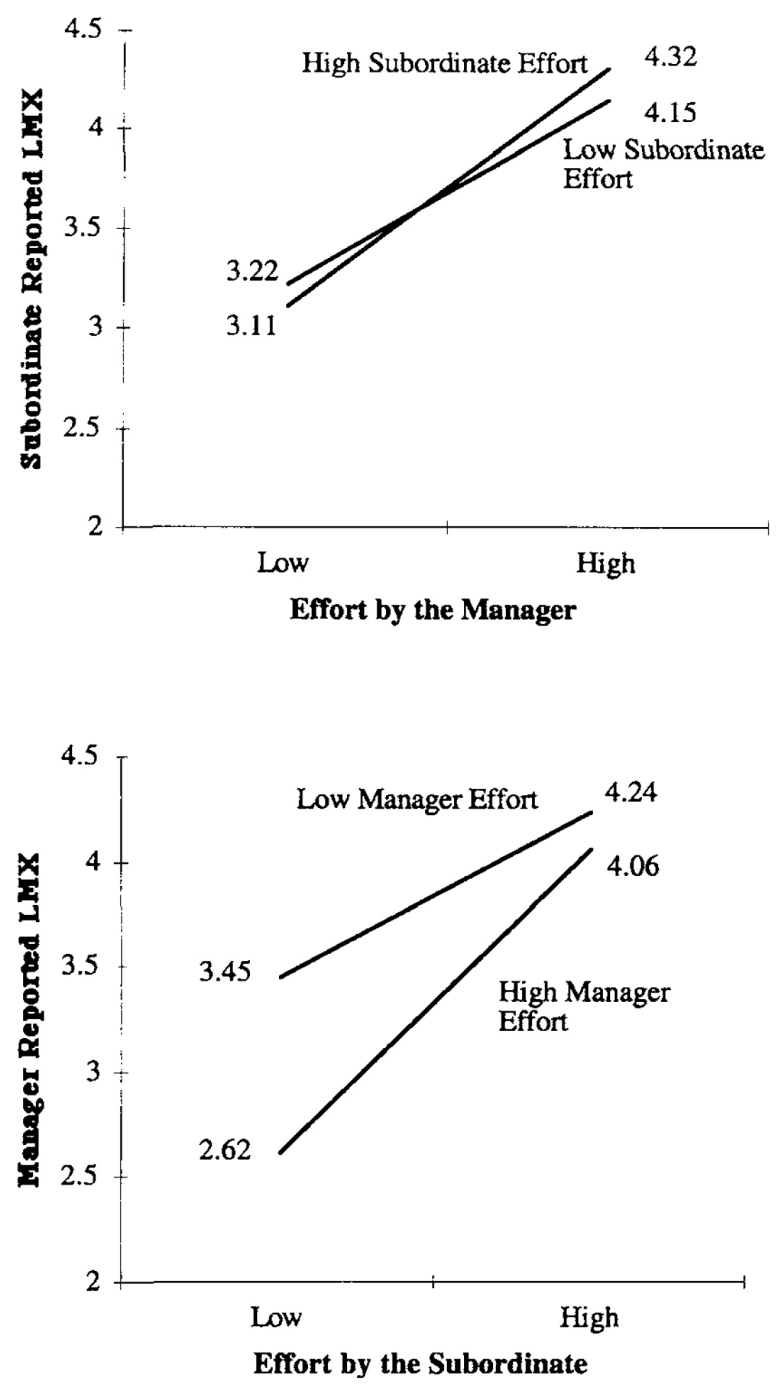

Figure 1. Interaction of self-effort and other's effort toward the development of leader-member exchange (LMX) by subordinates and managers.

quality and their dyadic tenure, such that higher levels of future effort would be reported by individuals who had good relationships for longer periods of time. Table 5 reports the results of hierarchical regression analysis showing dyadic tenure and LMX interacting to predict future effort, providing support for this hypothesis. Figure 2 shows details of the interaction, with regression lines of higher and lower LMX at higher and lower levels of dyadic tenure (again, levels were based on $\pm 1 S D$ from the mean for each variable). The interaction indicates that intended future effort was greatest when a higher quality relationship was coupled with longer dyadic tenure. These findings suggest that as tenure in the relationship increases, those in higher quality relationships intend to put forth increasing levels of effort while those in lower quality relationships intend to put forth the same amount of effort as those in shorter term relationships of lower quality.

In addition, because this is one of the first reported uses of both the LMX-7 and the LMX-MDM, we assessed the composite measure of the LMX-MDM (relative to the LMX-7) when overall relationship quality was a hypothesized independent or dependent variable. The results were very similar to, though not identical with, those using the LMX-7. In regression tests of Hypothesis 1a, subordinate reports of manager effort were significantly associated with the composite LMXMDM. In a similar manner, manager reports of subordinate effort (cross-dyad analysis) were significant, with subordinate effort positively related to the composite LMX-MDM. The interaction of subordinate reports of their own effort and effort by the manager (Hypothesis $1 \mathrm{~b}$ ) was significant at a marginal level $(p<.10$; slightly weaker finding than the LMX-7). As with the LMX-7, the interaction (Hypothesis 1b) was not significant in the cross-dyad analysis. Finally, in tests of the composite LMX-MDM with future effort as the dependent variable, the hypothesis (Hypothesis 4) regarding the interaction between relationship quality and dyadic tenure was not supported.

\section{Discussion}

In a test of key LMX issues, the findings of the present study show that effort made by dyad members is related to the quality of relationships that develop, but that effort by the dyad partner appears to be the critical factor associated with higher quality relationship formation. In both same-source and cross-dyad regression analyses, effort by the dyad partner was positively and significantly associated with LMX. As we hypothesized, the level of self-effort reported by the participants played a smaller role in light of judgments of the other member's effort, with one's own effort associated with LMX when other effort was low and then in a negative direction (found for both managers and subordinates in same-source but not cross-dyad regression analyses). Met expectations of relationship quality were positively associated with LMX, but effort by the dyad partner and reports of one's own effort showed differential effects with met expectations: Effort by the dyad partner was positively related and one's own effort was negatively related to met expectations (in three of four analyses). Taken together, these findings for effort and expectations show that managers and subordinates in higher quality LMX relationships reported greater effort by the dyad partner and higher levels of met expectations, whereas own effort was associated with lower met expectations. It is interesting that although no significant differences were found between mean levels of subordinates' reports of their own and other's effort, managers' reports of own effort were significantly higher than their reports of effort by the subordinate, indicating that they felt their own effort toward relationship development was greater than their subordinates' effort.

The findings also show that in situations of lower quality LMX individuals reported that the relationship did not develop as they had expected, suggesting that the relationship was a disappointment to lower LMX managers and subordinates. This is an important issue that has not been clearly addressed before in LMX research. Though we know that LMX is related to satisfaction with the relationship (Gerstner \& Day, 1997), it is less clear whether those in lower LMX relationships believed that the relationship could have been better. The findings of the present study indicate that individuals in these relationships wanted the relationships to be better and that they believed they tried, but the relationships did not work. Although future research is needed, such results suggest that individuals believe it is the other's fault, and this may be a stronger effect for managers, who reported greater overall effort by themselves than they reported for their subordinates. 
The study also examined the role of effort relative to dimensions of LMX, providing a somewhat more refined picture. Subordinates' reports of effort by the manager (i.e., effort by the dyad partner) were positively and significantly related to their reports of loyalty and professional respect in the relationship (social dimensions) but were not significantly related to their reports of contribution in the relationship (a work-related dimension) or affect. Contrary to predictions, managers'

Table 3. Regression Analysis of the Multidimensional Leader-Member Exchange Scale (LMX-MDM) on Subordinate and Manager Reports of Effort.

\begin{tabular}{|c|c|c|c|c|c|c|c|c|c|c|}
\hline \multirow[b]{2}{*}{ Variable } & \multicolumn{2}{|c|}{ LMX-MDM composite } & \multicolumn{2}{|c|}{ Contribution } & \multicolumn{2}{|c|}{ Professional respect } & \multicolumn{2}{|c|}{ Affect } & \multicolumn{2}{|c|}{ Loyalty } \\
\hline & Subordinate & Manager & Subordinate & Manager & Subordinate & Manager & Subordinate & Manager & Subordinate & Manager \\
\hline Subordinate age & .00 & -.01 & .05 & .08 & $-.10^{*}$ & $-.13^{* *}$ & .02 & -.02 & .06 & .09 \\
\hline Subordinate gender & .00 & -.06 & -.04 & -.02 & $.12^{* *}$ & .09 & -.05 & -.04 & -.07 & -.08 \\
\hline Dyadic tenure & .11 & .10 & .00 & .04 & -.02 & -.04 & .04 & .04 & .06 & .04 \\
\hline Contribution & & & & & $.23^{* *}$ & $.20^{* *}$ & .08 & $.13^{*}$ & $.20^{* *}$ & $.22^{* *}$ \\
\hline Loyalty & & & $.27^{* *}$ & $.29^{* *}$ & $.24^{* *}$ & $.26^{* *}$ & $.29^{* *}$ & $.34^{* *}$ & & \\
\hline Self-reported effort & -.01 & $-.26^{* *}$ & $.30^{* *}$ & -.12 & $-.19^{* *}$ & $-.17^{*}$ & .03 & .11 & -.03 & .01 \\
\hline $\begin{array}{l}\text { Reported effort by } \\
\text { the dyad partner }\end{array}$ & $.59 * *$ & $.66^{* *}$ & -.11 & .15 & $.19^{* *}$ & $.27^{* *}$ & .03 & -.08 & $.21^{* *}$ & .04 \\
\hline$F$ & $18.48^{* *}$ & $8.87^{* *}$ & $24.48^{* *}$ & $19.95^{* *}$ & $46.28^{* *}$ & $35.98^{* *}$ & $37.23^{* *}$ & $32.07^{* *}$ & $38.70^{* *}$ & $31.68^{* *}$ \\
\hline Adjusted $R^{2}$ & .33 & .20 & .50 & .48 & .66 & .63 & .61 & .60 & .62 & .60 \\
\hline
\end{tabular}

The dependent variables were provided only by subordinates. Values reported are standardized beta weights. Degrees of freedom for subordinate analyses were 6, 203 for the LMX-MDM composite and 9, 200 for each dimension and for manager analyses were 6, 178 and 9, 175, respectively. Gender was coded $1=$ male and $2=$ female .

${ }^{*} p<.05 .{ }^{* *} p<.01$.

Table 4. Regression Analysis of Subordinate and Manager Reports of Met Expectations on Subordinate and Manager Reports of Effort

\begin{tabular}{|c|c|c|c|c|c|c|}
\hline Variable & $\begin{array}{c}\text { Adjusted } \\
R^{2}\end{array}$ & $\Delta R^{2}$ & $\beta$ & $\begin{array}{c}\text { Adjusted } \\
R^{2}\end{array}$ & $\Delta R^{2}$ & $\beta$ \\
\hline & \multicolumn{5}{|c|}{ Subordinate reports of effort } & \\
\hline Overall equation & .41 & $.41^{* *}$ & & .12 & $.12^{* *}$ & \\
\hline Subordinate age & & & -.01 & & & .07 \\
\hline Dyadic tenure & & & -.01 & & & .14 \\
\hline LMX-7 & & & $.48^{* *}$ & & & $.26^{* *}$ \\
\hline Subordinate-reported effort & & & $-.28^{* *}$ & & & -.04 \\
\hline Subordinate reports of manager effort & & & $.34^{* *}$ & & & .09 \\
\hline
\end{tabular}

Overall equation

Subordinate age

Subordinate education

Subordinate gender

Dyadic tenure

Manager LMX

Manager-reported effort

Manager reports of subordinate effort

Manager reports of effort

.13
$.13^{* *}$

-.10
-.14
-.14
.00
.11
$-.27^{* *}$
$.51^{* *}$
$.41^{*}$

$$
\begin{aligned}
& -.09 \\
& -.08 \\
& -.09 \\
& -.01 \\
& .36^{*} \\
& -.25^{*} \\
& .57^{*}
\end{aligned}
$$

Degrees of freedom were 7,196 and 7, 171 for the subordinate reports of effort with subordinate- and manager-reported met expectations, respectively, and 7, 173 and 7, 183 for the manager reports of effort with LMX and manager-reported met expectations, respectively. Gender was coded $1=$ male and $2=$ female . LMX = leader-member exchange.

${ }^{* *} p<.01$. 
Table 5. Hierarchical Regression Analysis of Future Effort on LMX-7 and Dyadic Tenure.

\begin{tabular}{|c|c|c|c|}
\hline Variable & Adjusted $R^{2}$ & $\Delta R^{2}$ & $\beta$ \\
\hline Step 1 & .25 & $.25^{* *}$ & \\
\hline Subordinate age & & & -.01 \\
\hline Subordinate education & & & .01 \\
\hline Subordinate gender & & & $.14^{*}$ \\
\hline Dyadic tenure & & & .07 \\
\hline LMX-7 & & & $.44^{* *}$ \\
\hline Subordinate-reported effort & & & -.16 \\
\hline Step 2 & .27 & $.02^{*}$ & \\
\hline Dyadic Tenure x LMX-7 & & & $.52^{*}$ \\
\hline
\end{tabular}

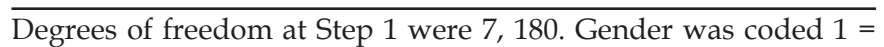
male and $2=$ female. $\mathrm{LMX}=$ leader-member exchange.

${ }^{*} p<.05 .{ }^{* *} p<.01$.

reports of subordinate effort (i.e., other effort) were not related to contribution. These results are not wholly consistent with the findings of Dockery and Steiner (1990) and Day and Crain (1992) that managers and subordinates seek different currencies of exchange from their partners (i.e., subordinates seek social and managers seek work-related currencies). The findings showed relative support for the predictions regarding subordinates, with the exception of affect, but lack of support for managers. Because this finding may have been due to the fact that we did not have supervisor LMX-MDM reports, we suggest that this as an area that should be explored further in future research.

In terms of their own effort, subordinates' reports of effort toward relationship development were positively related to contribution as predicted. For both managers and subordinates, own effort was negatively related to professional respect (as reported by the subordinates). When combined with the findings for other's effort (other's effort was positively related to respect for both managers and subordinates), these results suggest that effort may play a key role relative to respect in the relationship: Respect is greater when individuals see effort on the part of the dyad partner, but if they have to work too hard to develop the relationship, they have less respect for the other person. This finding is interesting because it suggests that the professional capabilities that the dimension of respect taps into may be related to the extent to which the individual works to develop relationships. Because this has not been clearly addressed in the literature, this possibility suggests another avenue for future research.

Finally, the findings on subordinates' intentions to exert future effort toward relationship development showed that future effort was most notably a function of the interaction between dyadic tenure and relationship quality. Subordinates who established higher quality LMX relationships and had been with their managers for the longest time showed the greatest intentions of putting forth effort in the relationship in the future. Employees with lower quality relationships reported lower intentions to exert future effort, seemingly regardless of tenure in the relationship.

This finding suggests a rationale for past reports of the stability of LMX relationships (Liden et al., 1993). Subordinates in lower quality relationships for any amount of time appear to express lower intentions to invest in relationship development, whereas as tenure in the relationship increases, in- dividuals in higher quality relationships report increasingly greater intentions toward future effort. This has an important implication for managers and subordinates in lower quality LMX relationships. Because subordinates in lower quality relationships are less likely to make an effort to change their status, managers may need to be the catalyst for change and initiate the steps necessary to build the quality of the relationship (Whitener et al., 1998). However, if subordinates do not respond to this attempt by demonstrating effort back to the manager, the relationship will likely not improve, and respect for one another will deteriorate. In these cases, the organization must endure subpar relationships and the resultant negative organizational consequences associated with them, including lower productivity, less job satisfaction, fewer extra-role behaviors, and so forth (Graen \& Uhl-Bien, 1995). Coupled with recent research showing the negative effects of differentiation (Maslyn \& Uhl-Bien, 1998), it is apparent that managers and subordinates must take positive steps to manage their lower quality relationships by getting their dyad partner to feel they are making efforts. Moreover, future research needs to investigate managers' reports of intended future effort to see how they compare with our findings for subordinates.

In terms of other theoretical and practical implications, this study helps shed light on individuals' perceptions about factors related to relationships that develop well versus those that develop poorly. The study also adds a different twist to work on antecedents to LMX already in the literature (Bauer \& Green, 1996; Deluga, 1998; Liden et al., 1993), extending understanding about member roles in the relationship in terms of effort toward relationship development. In addressing the question of whose effort is more important, the data show that, in support of social exchange theory, it is not the manager's or the subordinate's behavior per se that drives the relationship but rather the dyad partner's behavior (regardless of whether the partner is the manager or the subordinate) that is important for higher quality relationship development. Though the study was cross-sectional and did not allow us to test these issues in a dynamic interactive process, we propose that, consistent with social exchange, this behavior may represent the

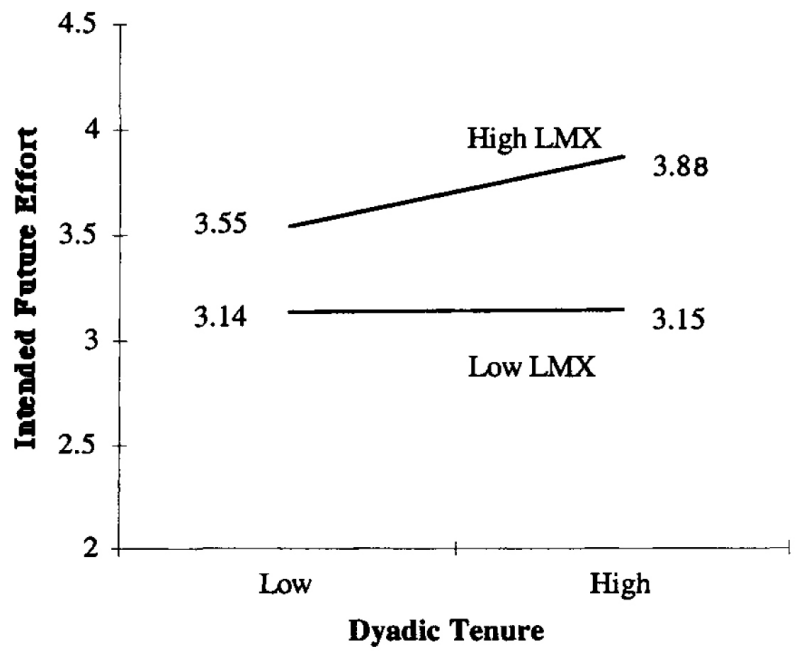

Figure 2. Interaction of leader-member exchange (LMX) and dyadic tenure in the prediction of intended future effort toward the managersubordinate relationship. 
reciprocation effort as seen by the dyad partner. In support of this suggestion, the finding that reports of higher levels of own effort and lower effort by the partner were accompanied by reports of lower LMX demonstrates to us that the individuals felt they worked hard at relationship development but the dyad partner did not pull his or her weight - an indication of a lack of reciprocation in the relationship. When such unbalanced effort was reported, respect in the relationship was lower (i.e., respect was positively related to other's effort and negatively related to own effort in the regression analyses). Because reciprocity was not the focus of this research, however, these issues need to be further explored in future studies.

A major strength of this study lies in the consistency of results in both the same-source and cross-dyad analyses. Not only does this strengthen the findings about judgments of effort on the part of the other member of the dyad, but it also lends support to much past research that has found similar judgments of overall LMX quality (e.g., Deluga \& Perry, 1994; Duchon et al., 1986; Liden \& Graen, 1980). The extension of these tests for the few variables that we were not able to collect from supervisors (e.g., LMX-MDM, future effort) is recommended for future research.

The use of both the LMX-7 and the LMX-MDM is another strength of this study. The LMX-MDM is a relatively new measure that allowed us to examine dimensionality as well as overall quality of LMX relationships. The real value of the LMX-MDM for this study was in the unique effects found for the varying dimensions. However, although Liden and Maslyn (1998) suggested that the composite LMX-MDM measure could be used as a replacement for the LMX-7 when dimensions of LMX were not the focus of the research, the composite LMX-MDM did not consistently show the same pattern of results as the LMX-7. Therefore, we suggest that future work be conducted on these two measures to examine how they interrelate.

Despite the strong test-retest reliability and the additional test for social desirability, this study did use some single-item measures. The consistency of findings across multiple tests for both supervisors and subordinates partially alleviates concern about the validity of the single-item measures, but we suggest that these findings be replicated with multiple-item measures. The internal consistency of the contribution measure (.66) presents another potential problem of measurement. Because the use of the contribution dimension often resulted in unique findings, replication is suggested. The study also looked at a recall measure of LMX development and was based on a crosssectional design using existing dyads. As such, we were not able to capture information about who made the initial effort or whether such effort was immediately reciprocated. We suggest that the questions examined in this study be tested using a longitudinal approach.

In conclusion, this article provides a first real insight into the nature of relative effort in LMX relationships and how it is associated with LMX quality and met expectations, as well as intentions to exert future effort into relationship development. The research answers questions central to LMX theory that have remained unaddressed in the literature to date. Though we believe the study suggests implications for social exchange and reciprocity in LMX relationships, the research design did not allow for a true test of reciprocity because of its cross-sectional nature. Therefore, future research needs to further explore these issues, because they are at the heart of LMX.

\section{References}

Bauer, T. N., \& Green, S. G. (1996). Development of leader-member exchange: A longitudinal test. Academy of Management Journal, 39, 1538-1567.

Blau, P. (1964). Exchange and power in social life. New York: Wiley.

Burgess, R. L., \& Huston, T. L. (1979). Social exchanges in developing relationships. New York: Academic Press.

Buunk, B. P., Jan Doosje, B., Jans, L. G., \& Hopstaken, L. E. (1993). Perceived reciprocity, social support, and stress at work: The role of exchange and communal orientation. Journal of Personality and Social Psychology, 65, 801-811.

Cogliser, C., Schriesheim, C., Scandura, T., \& Neider, L. (1999, August). Balanced and unbalanced leadership relationships: A three-sample investigation into the outcomes associated with four different types of leader-member exchanges. Paper presented at the annual meeting of the Academy of Management, Chicago, IL.

Cohen, J., \& Cohen, P. (1983). Applied multiple regression/correlation analysis for the behavioral sciences (2nd ed.). Hillsdale, NJ: Erlbaum.

Crowne, D. P., \& Marlowe, D. (1960). A new scale of social desirability independent of psychopathology. Journal of Consulting Psychology, 24, 349-354.

Day, D. D., \& Crain, E. C. (1992). The role of affect and ability in initial exchange quality perceptions. Group and Organization Management, 17, 380-397.

Deluga, R. J. (1998). Leader-member exchange quality and effectiveness ratings. Group and Organization Management, 23, 189-216.

Deluga, R. J., \& Perry, J. T. (1994). The role of subordinate performance and ingratiation in leader-member exchanges. Group and Organization Management, 19, 67-86.

Dienesch, R. M., \& Liden, R. C. (1986). Leader-member exchange model of leadership: A critique and further development. Academy of Management Review, 11, 618-634.

Dockery, T. M., \& Steiner, D. D. (1990). The role of the initial interaction in leader-member exchange. Group \& Organization Studies, 15, 395-413.

Duchon, D., Green, S. G., \& Taber, T. D. (1986). Vertical dyad linkage: A longitudinal assessment of antecedents, measures, and consequences. Journal of Applied Psychology, 71, 56-60.

Gardner, D. G., Cummings, L. L., Dunham, R. B., \& Pierce, J. L. (1998). Single-item versus multiple-item measurement scales: An empirical comparison. Educational and Psychological Measurement, 58, 898-915.

Gerstner, C. R., \& Day, D. V. (1997). Meta-analytic review of leadermember exchange theory: Correlates and construct ideas. Journal of Applied Psychology, 82, 827-844.

Ghiselli, E. E., Campbell, J. P., \& Zedeck, S. (1981). Measurement theory for the behavioral sciences. San Francisco: Freeman.

Graen, G. B., \& Scandura, T. A. (1987). Toward a psychology of dyadic organizing. In B. M. Staw \& L. L. Cummings (Eds.), Research in organizational behavior (Vol. 9, (pp. 175-208). Greenwich, CT: JAI Press.

Graen, G. B., \& Uhl-Bien, M. (1995). Relationship-based approach to leadership: Development of leader-member exchange (LMX) theory of leadership over 25 years: Applying a multi-level multidomain perspective. Leadership Quarterly, 6, 219-247.

Homans, G. C. (1958). Social behavior as exchange. American Journal of Sociology, 63, 597-606.

Liden, R. C., \& Graen, G. B. (1980). Generalizability of the vertical dyad linkage model of leadership. Academy of Management Journal, 23, 451-465. 
Liden, R. C., \& Maslyn, J. M. (1998). Multidimensionality of leadermember exchange: An empirical assessment through scale development. Journal of Management, 24, 43-72.

Liden, R. C., Sparrowe, R. T., \& Wayne, S. J. (1997). Leader-member exchange theory: The past and potential for the future. In G. R. Ferris \& K. M. Rowland (Eds.), Research in personnel and human resources management (Vol. 15, (pp. 47-119). Greenwich, CT: JAI Press.

Liden, R. C., Wayne, S. J., \& Stilwell, D. (1993). A longitudinal study on the early development of leader-member exchanges. Journal of Applied Psychology, 78, 662-674.

Maslyn, J. M., \& Uhl-Bien, M. (1998, August). Self and coworker views of leader-member exchange (LMX) relationships: Perceptions of ingratiation and fairness. Paper presented at the annual meeting of the Academy of Management, San Diego, CA.

Mauss, M. (1950). The gift: The form and reason for exchange in primitive societies. New York: Norton.

Newcomb, T. M. (1961). The acquaintance process. New York: Holt, Rinehart \& Winston.

Pedhazur, E. J. (1982). Multiple regression in behavioral research. Fort Worth, TX: Holt, Rinehart \& Winston.

Porter, L. W., \& Steers, R. M. (1973). Organizational, work, and personal factors in employee turnover and absenteeism. Psychological Bulletin, 80, 151-176.

Rousseau, D. M. (1998). LMX meets the psychological contract: Looking inside the black box of leader-member exchange. In F. Dansereau \& F. J. Yammarino (Eds.), Leadership: The multiple level approaches, contemporary and alternative (pp. 149-154). Stamford, CT: JAI Press.

Sackett, P. R., \& Larson, J. R., Jr. (1990). Research strategies and tactics in industrial and organizational psychology. In M. D. Dunnette \& L. M. Hough (Eds.), Handbook of industrial and organizational psychology (2nd ed., Vol. 1, (pp. 419-489). Palo Alto, CA: Consulting Psychologists Press.

Scandura, T. A., \& Graen, G. B. (1984). Moderating effects of initial leader-member exchange status on the effects of a leadership intervention. Journal of Applied Psychology, 69, 428-436.

Schriesheim, C. A., Hinkin, T. R., \& Podsakoff, P. M. (1991). Can ipsative and single-item measures produce erroneous results in field studies of French and Raven's (1959) five bases of power? An empirical investigation. Journal of Applied Psychology, 76, 106-114.

Schriesheim, C. A., Neider, L. L., Scandura, T. A., \& Tepper, B. J. (1992). Development and preliminary validation of a new scale (LMX-6) to measure leader-member exchange in organizations. Educational and Psychological Measurement, 52, 135-147.

Sparrowe, R. T., \& Liden, R. C. (1997). Process and structure in leader-member exchange. Academy of Management Review, 22, 522-552.

Strahan, R., \& Gerbasi, K. C. (1972). Short, homogenous versions of the Marlowe-Crowne Social Desirability Scale. Journal of Clinical Psychology, 28, 191-193.

Uhl-Bien, M., Graen, G., \& Scandura, T. (2000). Implications of leader-member exchange (LMX) for strategic human resource management systems: Relationships as social capital for competitive advantage. In G. R. Ferris (Ed.), Research in personnel and human resources management (Vol. 18, (pp. 137-185). Greenwich, CT: JAI Press.

Vecchio, R. P. (1997). Are you in or out with your boss?. In R. P. Vecchio (Ed.), Leadership: Understanding the dynamics of power and influence in organizations (pp. 274-277). Notre Dame, IN: University of Notre Dame Press.

Walster, E., Walster, G. W., \& Berscheid, E. (1978). Equity: Theory and research. Boston: Allyn \& Bacon.

Wanous, J. P., Reichers, A. E., \& Hudy, M. J. (1997). Overall job satisfaction: How good are single-item measures? Journal of Applied Psychology, 82, 247-252.

Wayne, S. J., Liden, R. C., \& Sparrowe, R. T. (1994). Developing leader-member exchanges: The influence of gender and ingratiation. American Behavioral Scientist, 37, 697-714.

Wayne, S. J., Shore, L. M., \& Liden, R. C. (1997). Perceived organizational support and leader-member exchange: A social exchange perspective. Academy of Management Journal, 40, 82-111.

Whitener, E. M., Brodt, S. E., Korsgaard, M. A., \& Werner, J. M. (1998). Managers as initiators of trust: An exchange relationship framework for understanding managerial trustworthy behavior. Academy of Management Review, 23, 513-530. 